\title{
LOS ANNALES Y LA HISTORIOGRAFÍA FRANCESA
}

\author{
Carlos Mallorquín \\ Unidad Académica de Estudios del Desarrollo, UAZ
}

Carlos A. Aguirre hace un interesante relato sobre el surgimiento y crecimiento de una escuela historiográfica dominante hasta el día de hoy. Nada de cuentos y sí una descripción del vocabulario braudeliano. En 1929 se lanzan, formalmente, los Annales d'Historie Économique et Sociale, proyecto que en 1946 derivará en los Annales. Économies. Societies. Civilisations, que hoy día se identifica con el nombre de Fernand Braudel. De ese relato emerge la noción de que nuestros trópicos fueron una fuente de inspiración crucial para su constitución.

En Brasil descubrí lo que no conocía hasta cierto punto violenta (...) En todo caso, es en Brasil que yo me convertí en lo que ahora soy.

FERnANd BRAUdeL

En su lugar, trataría de no olvidar el continente descubierto por Alvares Cabral. (...) Entonces, usted se convertiría, al mismo tiempo, en un historiador mediterráneo y brasileño.

$Y$ necesitamos de ambos

L. FEVBRe (carta para Fernand Braudel)

I nicialmente, los Annales d'Historie Économique et Sociale tuvieron al frente a Marc Bloch y Lucien Febvre, quienes habían estado examinando y renovando aspectos de la obra de Henri Berr y Henri Pirenne. De hecho, existe un fenómeno latinoamericano en genealogía formativa sobre la obra y formación de Braudel. Se sabe que, para Lucien Febvre, América del Sur era un "campo privilegiado de estudios". ${ }^{1}$ Entre 1935-1937, la recientemente fundada Facultad de Filosofía, Ciencias y Letras de la Universidad de Sao Paulo, tiene a Fernand Braudel como uno de los profesores de la cátedra de "Historia de las Civilizaciones". Entonces, Braudel no formaba parte del grupo dirigente de los primeros Annales.

La influencia pionera de Henri Hauser - miembro del comité de Dirección de Annales- en Brasil también estuvo en la Universidad de Río de Janeiro, entre 1936 y 1939. Brasil conforma un espacio sui generis donde se encuentran la corriente historiográfica francesa y América Latina. En ese país la proyección "annalista" obtuvo un lugar predominante. Brasil es altamente receptivo a la cultura francesa. ${ }^{2}$ En 1947, Braudel realizó una segunda estancia de cinco meses en la Universidad de Sao Paulo, y de esa manera los Annales seguirán ampliando su influencia intelectual, especialmente en hombres como Florestán Fernández Alicia Cannabrava, Eduardo d'Oliveira Franca, Octavio Ianni, Celso Furtado y Charles Morazé (Les Trois ages du Brasil: essai de politique) -también miembro del comité de Dirección de los Annales-, así como en Fréderic Mauro, después de la Segunda Guerra Mundial.

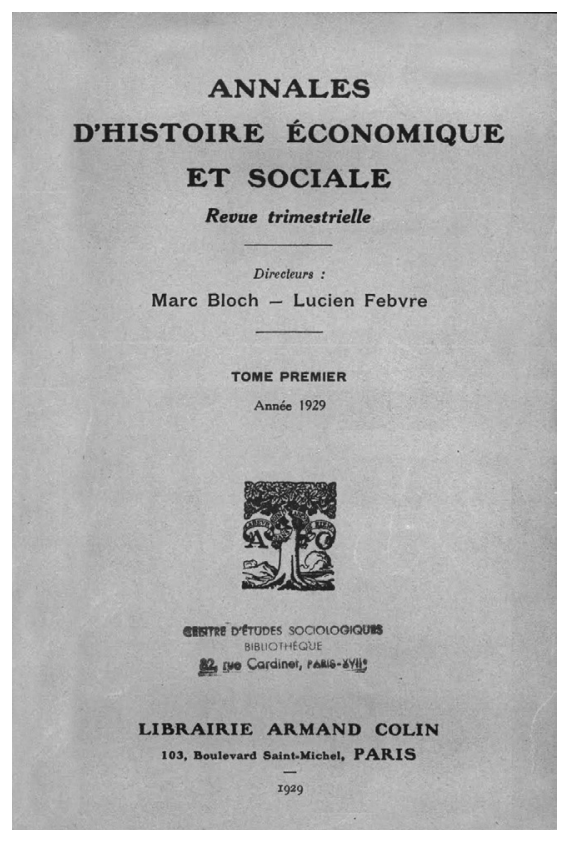

Los Annales rompieron con las figuras de los grandes personajes, los eventos universales o las coyunturas: la idea de la historia comparativa y la historia global suponía pensar espacios y tiempos "diferenciales". A los heréticos Annales iniciales se sobrepondrá, después de la Segunda Guerra Mundial, durante su periodo braudeliano, la confirmación de un tercer Annales, con la noción primordial de "larga duración" ("como un personaje embarazoso complejo, con frecuencia inédito. Admitirlas en el seno de nuestro oficio no puede representar un simple juego"). ${ }^{3}$

En su primera época, Bloch se concentra en la historia económica y social, agraria o rural, y Febvre en la historia de las mentalidades y movimientos culturales 
en los orígenes del capitalismo, integrando ciertos fenómenos al resto del todo orgánico. El análisis no se aborda en blanco por el investigador sino a través de problemas, he allí la idea de los primeros Annales, la "historia-problema", y la importancia de una reelaboración crítica de los materiales y explicaciones previas.

No tratan los fenómenos "espectaculares" o más llamativos, surgen los "grises y cotidianos" ${ }^{4}$ movimientos de los precios, las curvas de salario, la organización del trabajo y sus cambios. Por lo tanto, "historia problema" e "historia global", lo cual, a su vez, supone una noción multicausal en la determinación de las relaciones sociales, sin presuponer la primacía política debido a una determinación económica en particular.

Los Annales se sublevaron contra una vieja tradición en las ciencias sociales. La explicación de las relaciones sociales del pasado excluyendo las del presente, debido a que supuestamente son fenómenos examinados por otras disciplinas, queda superada. Esa tradición decía garantizar el "rigor" y "objetividad" de los "hechos". La misma noción de "neutralidad" en la descripción para esa vieja tradición ("tal y como acontecieron"), quedó desplazada. En otras palabras, los Annales piensan que no hay objeto, método y frontera - preconcebidos y establecidos-para explicar las relaciones sociales. Más bien, el saber no está acartonado, la historia no es solamente ciencia del pasado, sino ciencia de las "obras humanas", en cualquier periodo o momento posible. Se apoya en una gran variedad de huellas que ha dejado el ser humano, sin excluir los documentos escritos de la época, ya que es el "historiador quien da luz a los hechos históricos, incluso los más humildes". 5

Tanto el marxismo y los Annales hacen historia criticando la tradición anterior, cuya concepción de las relaciones sociales aparentaba rigurosidad utilizando descripciones "neutrales" de los hechos ("empirista" y positivista). La estrategia de diferenciación de los $A n$ nales inicia pensando la historia y las relaciones como proceso global o total. Es una "historia problemática". ${ }^{6}$ Va desde "el todo hacia la delimitación de la parte que se quiere analizar y no a la inversa"; "historia abierta o en construcción", algunos dicen que "hacían marxismo sin saberlo". Bloch y Febvre no hacen, sin embargo, un Annales marxista, pero tiene cierta filiación comunista o de izquierda. ${ }^{7}$

Como dijimos, los primeros Annales son un pequeño grupo inconforme con las explicaciones sobre cómo hacer ciencia social e historia. Contra la forma empirista de concebir los procesos sociales e históricos, que se concentra en los "hechos" y privilegia los documentos escritos para acceder a dichos fenómenos sociales (que se cree algo "objetivo"), los Annales (1929-39) piensan en términos globales o totalizantes, incorporando una serie de disciplinas conexas. ${ }^{8}$ Ninguna concepción ingenua de los hechos, más bien una descripción problemática de las relaciones sociales y su medio ambiente.

Al final de la Segunda Guerra Mundial se abre una nueva fase de los Annales que se prolonga hasta 1956, cuando fallece Febvre; entonces Braudel toma la dirección efectiva de la revista e inician los "Annales segundos" o "Annales braudelianos", esta época puede alargarse hasta 1969 (con Emmanuel Le Roy Ladurie, Francois Furet, Jaques Legoff).

El tercer Annales inicia a comienzos de los setentas. Son los fenómenos de larga duración y la historia total. Braudel abandona la dirección en 1969, y la toman Emmanuel Le Roy Ladurie, Marc Ferro, Jaques Legoff. Dicho periodo culminará en 1989. Los Annales dejan la historiografía económica y social, temática central de los primeros y segundos Annales, y desarrollan temas como la historia de las mentalidades. Abandonan las discusiones metodológicas del oficio de historiador y ejercer el analista social.

Desde Pirenne, surge el problema de identificar aquellos acontecimientos históricos cruciales, separándolos de los que Braudel llama "polvo de historia". Braudel, al igual que Marx, concibe las relaciones sociales y su explicación como una ciencia de lo general, tomando a la "globalidad" como su "centro" para iniciar las investigaciones. Es decir, implica suponer que lo social tiene una unidad específica, ya que lo contemporáneo se explica frente al pasado. Por eso Braudel dice que las "ciencias sociales terminarán por fin un día reuniéndose en una sola experiencia". ${ }^{9}$

De ser una corriente claramente minoritaria hasta 1939, se torna casi hegemónica después de la Segunda Guerra Mundial. En 1946 retoma su antiguo papel bajo el título de Annales. Économies. Societies. Civilisations, y en los siguientes diez años (con la muerte de Febvre en 1946) se enfrasca en una transición. De 1956 a 1968 encontramos la segunda etapa, donde Braudel dirige la línea: se ordena y propone, de modo más coherente y explícito, la idea de la larga duración en la historia y la visión de las temporalidades diferenciales; se desarrolla el concepto de "civilización material" y el análisis de la "infraeconomía", desde la cuestión del clima y el recuento de los hábitos alimenticios o formas de la vivienda al del mobiliario entre distintas culturas y civilizaciones.

Lo social-humano requiere, entonces, historias o explicaciones globalizantes, totalidades, tanto de los procesos económicos como de los fenómenos que corresponde a las mentalidades y su entorno natural. Tomando como obligación de manera simultánea y profunda todas y cada una de las esferas que abarca ese campo u objeto de investigación de lo social-humano, como entidad natural e histórica. 
La globalidad no es la pretensión de escribir una historia total del mundo. No es esta pretensión pueril, simpática y desatinada. Es simplemente la intención, cuando se ha abordado un problema, de sobrepasar sistemáticamente los límites. No hay problema de historia, desde mi punto de vista, que esté cercado de muros, que sea independiente. ${ }^{10}$

Los Annales parecen defender cierta multicausalidad que aparenta un "relativismo", pero que se explica por las influencias y conexiones desiguales entre los fenómenos sociales históricos, por la misma asimetría entre los diferentes planos de la realidad.

El problema de "leyes" en la historia se elude sistemáticamente por la ausencia de una determinación unívoca entre los aspectos sociales y ambientales. El marxismo vería la postura como inadecuada, ya que se presume, en algún sentido, cierta primacía de lo "económico". Tal vez existe cierto relativismo extremo en los primeros Annales, dirán los marxistas, que la haría incompatible con la concepción materialista de la historia.

Los Annales segundos, con la incorporación de Braudel, se enfrentarán a los problemas mencinados. En El Mediterráneo y el mundo mediterráneo en la época de Felipe II, Braudel no trata la historia de un rey, un pueblo o la nación, sino de reconstruir un mar y del mundo en torno a él. Esencialmente, es el análisis de un ámbito "natural", humanizado y fuente de un desarrollo global ("un estudio histórico entrado sobre un espacio líquido encierra todos los encantos, pero también, y más todavía, todos los peligros de una novedad"). ${ }^{11}$ Son fundamentos geográfico-naturales, fundacionales de todo proceso social posible. No se trata de hacer la geografía de una región, sino de mostrar el "verdadero nexo orgánico entre este basamento natural y los restantes planos de la totalidad social de que se trate."12

Igualmente se observa en los estudios de los Annales "la montaña", las formas de vida y de la consciencia que consiste en no tenerla, puesto que permanece al "margen de las grandes corrientes civilizadoras". ${ }^{13}$ Persistencia de los hombres montañeses cuyos hábitos, comportamientos y papel en la historia no hacen más que testimoniar la decisiva influencia de ciertos elementos naturales sobre la vida humana. Así también, la civilización agraria, y su influencia sobre las relaciones sociales, cuyos ritmos quedan determinados por la vida económica que hace posible.

De cierta manera, comparte, con la concepción materialista, la idea de abarcar de manera global esos fenómenos, donde las condiciones naturales o fundamentos geográfico-naturales de la propia vida y evolución humana explican las formas de reproducción.

Esta recuperación de lo geográfico-natural se deriva de la diferenciación de los tiempos que tanto resalta Braudel:

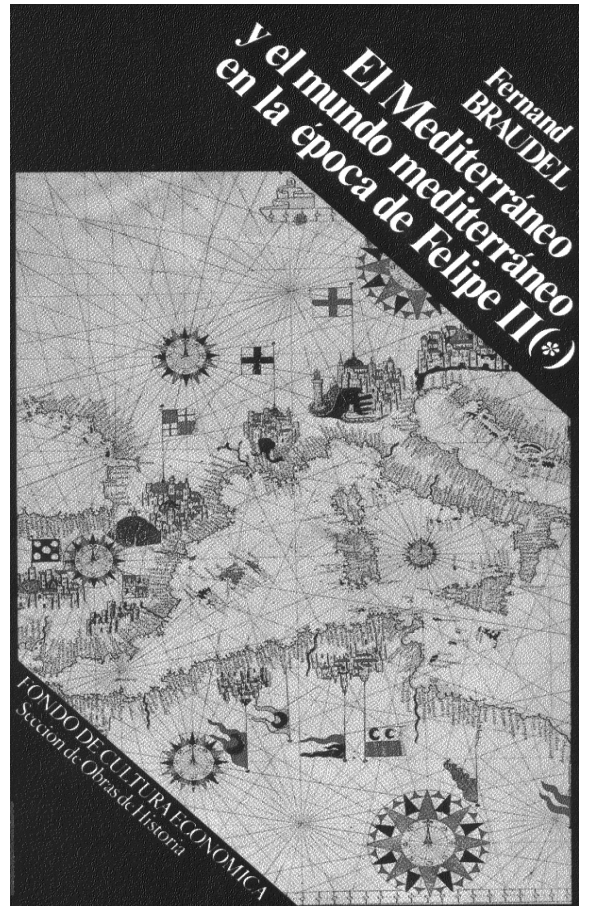

los ritmos de movimiento y de cambio, de vigencia y de duración de los distintos planos considerados no son en absoluto idénticos y ni siguiera similares: mientras el plano de los basamentos naturales es el plano de la "historia casi inmóvil" y el nivel de las economías, de las sociedades, de las civilizaciones y de los Estados es en cambio "una historia de ritmo lento", la esfera de los acontecimientos políticos y de los hechos individuales más importantes es por su parte "una historia de oscilaciones breves rápidas y nerviosas". ${ }^{14}$

La síntesis compleja de las relaciones sociales y su historia se presenta con temporalidades distintas, ritmos diversos de duración. Temporalidad y duración diferenciales de los diversos hechos y fenómenos históricos que de alguna manera también lo percibió Marx en las periodizaciones que hace de las épocas humanas a través del modo de producción. Así, podemos percibir rasgos sociales de "larga duración" de los que habla Braudel, donde el "predodominio de lo natural" queda corroborado vía el análisis de la vida económica.

La civilización material va quizás más allá que la perspectiva de Marx:

los usos repetidos, los procedimientos empíricos, las muy viejas recetas, las soluciones venidas de la noche de los tiempos, como la moneda o la división de ciudades y campos (...)" hechos y realidades elementales y durables que registran la progresiva respuesta adaptativa de los hombres frente a la naturaleza y a sus coacciones básicas, 
hechos tales como el de que "se siembre el trigo como siempre se ha sembrado, se planta el míaz como siempre se ha plantado, se allana la tierra del arrozal como siempre se ha allanado. ${ }^{15}$

El plano de la infraeconomía, lo que subyace a las estructuras económicas, a las que influye y limita de manera fundamental cobra vida muy particular en la perspectiva de los Annales. En otras palabras, se trata de "estudiar las distintas coacciones geográficas, biológicas y naturales que el mundo de la naturaleza impone al hombre, y la respuesta adaptativa y progresivamente transformadora que este último realiza frente a la primera."16

Finalmente, la idea del libro es inspirar el estudio en las ciencias sociales; o parafraseando al propio Engels, no se trata de que sea recibido por "un montón de amigos a quienes les sirva de excusa para no estudiar la historia". ${ }^{17}$

Referencias

${ }^{1}$ Aguirre, Carlos (1996), Los Annales y la Historiografía Francesa, México, Ediciones Quinto Sol, p. 9.

${ }^{2}$ El Instituto Francés de América Latina (IFAL) funda oficinas en México, en 1944; en Santiago de Chile en 1947; y en Colombia al siguiente año. En México, Francios Chevalier, discípulo de Marc Bloch, y Paul Rivet, quien dirigió la Encyclopedie Francaise coordinada por Febvre, realiza los trámites.

${ }^{3}$ Braudel apud. Aguirre (1996:34).

${ }^{4}$ Aguirre (1996:77).

${ }^{5}$ Febvre apud. Aguirre (1996:71).

${ }^{6}$ Febvre apud. Aguirre (1996:71).

${ }^{7}$ Aguirre (1996:45).

${ }^{8}$ Aguirre (1996:69).

${ }^{9}$ Braudel apud. Aguirre (1996:63).

${ }^{10}$ Braudel apud. Aguirre (1996:73).

${ }^{11}$ Braudel apud. Aguirre (1996:82).

${ }^{12}$ Braudel apud. Aguirre (1996:82).

${ }^{13}$ Aguirre (1996:83).

${ }^{14}$ Braudel apud. Aguirre (1996:85).

${ }^{15}$ Aguirre (1996:89).

${ }^{16}$ Aguirre (1996:91).

${ }^{17}$ Engels apud. Aguirre (1996:59).

\section{Recomendaciones}
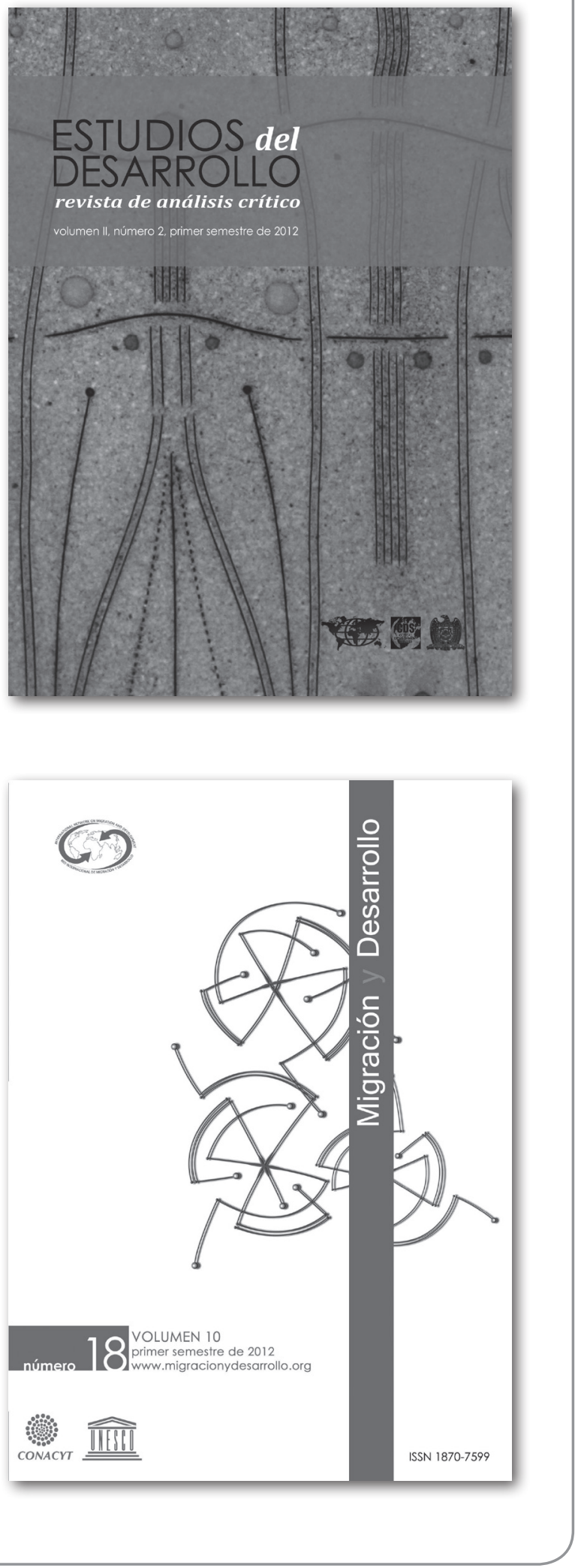